\title{
The First Person
}

\begin{abstract}
In this playful meditation on academic pronouns, I report on my research findings from three separate studies: a 2007 analysis of pronoun usage patterns in 50 higher education articles published 2006-2007; a 2017 analysis of the 70 articles published in Teaching \& Learning Inquiry since the journal was founded in 2013; and an updated analysis (2016-2017) of 50 articles from the same higher education journals examined a decade earlier. You may be surprised by the results. However, we are not inclined to reveal the whole story here in the abstract. It is the conviction of the author that the present article must be read in its entirety in order to be fully appreciated.
\end{abstract}

\section{KEYWORDS}

pronoun usage, first-person pronouns, second-person pronouns, third-person pronouns, higher education

\section{THE FIRST PERSON}

I am the first person. Some call me Adam. As a real-life female rather than a mythical male, I prefer to be called Helen. But how strange it feels to name myself in an academic article, even when I'm employing first person singular pronouns! I'm used to seeing my name as a byline or a citation, not as a proper noun in my own work. And already, just a few lines into this opening paragraph, I find myself banging up against the various dilemmas of the first person academic author: How personal should I get? Is authenticity my central aim, or am I striving to connect with my audience, or what? To what extent is the Iin this piece actually $m e$ ?

I first decided to write an article/creative contribution/think piece about personal pronoun usage after chatting with Nancy Chick and Gary Poole, the founders and co-editors of Teaching \& Learning Inquiry (TLI), following my closing keynote at the 2017 International Society for the Scholarship of Teaching \& Learning (ISSOTL) conference in Calgary. In my talk, I had displayed two graphs that caught their attention. The first one (figure 1), based on research that I undertook for my 2012 book Stylish Academic Writing, shows the relative frequency of first person pronoun usage in 50 articles from five topranked higher education research journals: Studies in Higher Education, Higher Education, Journal of Higher Education, Research in Higher Education, and Review of Higher Education. Only slightly more than half of these articles ( 52 percent) employ the pronouns $I$ or we, a significantly lower percentage than I found in similar samples of articles from other disciplines such as psychology ( 84 percent), literary studies (96 percent), or evolutionary biology (100 percent-so much for the myth that scientists always write in an impersonal mode!) (Sword, 2012, p. 17). 
Figure 1: Relative pronoun usage (first person or third person) and authorship patterns (single or multiple) in 50 articles from the five top-ranked higher education research journals in 2006-2007 (10 articles per journal). Average number of authors per article: 1.8 .

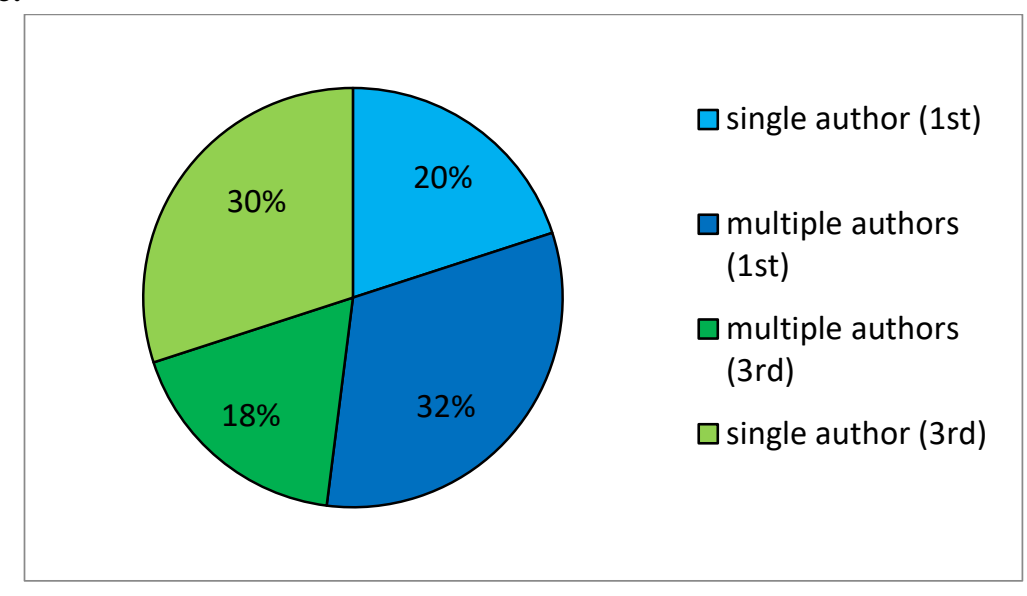

Given that exactly half of the higher education articles in my study (25 out of 50) were published by single authors, while the other half were written by multiple authors working in teams ranging from two to five people, I was curious to know whether solo authors are more likely to employ first person pronouns than are multiple-author teams, or vice versa. As the pie graph shows, multiple author teams (32 percent) proved somewhat more likely than single authors ( 20 percent) to write in the first person, and single authors (30 percent) proved somewhat more likely than multiple authors (18 percent) to avoid first person pronouns and write in an impersonal voice. Overall, however, there appeared to be no particularly strong relationship between authorship numbers and pronoun choice; each of the four groups gets a decent slice of the pie.

Figure 1, as I noted in my keynote, conveys two seemingly contradictory messages. On the one hand, it depicts the confused identity of a relatively young discipline that, at least at the time of my 2007 study, had not yet figured out its own pronoun conventions. For me, as a literary scholar who at that stage was dipping my toe into higher education research for the first time, it was somewhat disconcerting to realize that I was entering a discipline where there were no clear rules, no carefully marked swimming lanes. On the other hand, my findings suggested that authors who aspire to publish in higher education journals face no real constraints when it comes either to authorship numbers (single versus multiple) or pronoun usage ( $I /$ we versus third person prose). Emboldened by this discovery, I pitched a stylistically unconventional account of my findings to Studies in Higher Education, the top-ranked higher education journal at the time. The article eventually appeared under the title "Writing higher education differently: A manifesto on style" (Sword, 2009); I remain eternally grateful to editor Malcolm Tight for having the gumption to publish an article that so cheekily critiqued the dominant writing style of the very journal in which it appeared.

Preparing for my 2017 ISSOTL keynote, I realized that my research findings from that article were now more than a decade old. Moreover, the 50 articles that I analyzed had appeared in higher education research journals rather than specifically in Scholarship of Teaching \& Learning (SoTL) journals; thus the research might not be entirely relevant to the conference audience I would be 
addressing. I therefore decided to conduct a new survey examining pronoun usage in TLI, the official ISSOTL journal, which did not yet exist at the time of my original study. Seventy articles had been published in TLI since its establishment in 2013; I asked my research assistant, Madeleine Ballard, to survey them all.

\section{THE FIRST PERSON PLURAL}

When Madeleine joined the research project, $I$ became we. But before we proceed with our discussion of the data, it behoves us to consider what kind of collective entity the word we is meant to represent. Are we referring to a specific group of speakers ("we, the authors")? To the author(s) plus our intended readers ("we, SoTL scholars")? Or is we just a covert way of saying "I, the author" without uttering the dreaded pronoun $I$ ? The latter formulation, technically called a "nosism" but often referred to as "the royal we," still occasionally wafts from the lips of the Queen but has become nearly as rare in academic prose as phrasings such as "the latter" and "it behoves us." In 1975, physicist Jack H.

Hetherington famously added his cat Chester (aka Felis Domesticus Chester Willard, shortened to FDC Willard) as his co-author, an ingenious way of turning I into we (Stall, 2007, p. 22). We will not stoop to such machinations. Instead, our pronoun choice is intended to denote two real people: the author of this article, Helen, plus her research assistant, Madeleine, a usage that linguists dub "the exclusive we" because it shuts out all other subjects (Harwood, 2005b).

Having identified every article ever published in TLI (not counting editorials, book reviews, and creative pieces), we downloaded all 70 articles and created a spreadsheet listing their authors, titles, and publication dates. Next, we analyzed their pronoun usage patterns and authorship numbers. (Actually, Madeleine did most of the work while Helen merely supervised; but such distinctions get lost when we refer to ourselves collectively.)

\section{THE SECOND PERSON}

You were probably wondering when you, the reader, would get a chance to speak, or at least to be spoken to. Or maybe you weren't, especially if you don't enjoy reading second person texts that put words in your mouth or employ the pronoun you when the author clearly means $I$. Poets sometimes use such ploys to collapse the distance between writer and reader, as when Rainer Maria Rilke ends his poem "Archaic Torso of Apollo" with the startling final line, "You must change your life": the headless statue's imagined admonition to the poet in turn becomes the poet's admonition to his readers (Rilke, 1995, p. 68). Novelist Jay McInerney went so far as to publish an entire novel, Bright Lights, Big City, written in the second person singular (1984). If, like the main character of McInerney's novel, you are a disaffected twenty-something Ivy League graduate living in New York in the early nineteen-eighties, incessantly snorting cocaine and whining about your pathetic, privileged life, you may feel a close personal connection to the you of the book. Otherwise, you are likely to find the gimmick quite annoying.

But enough about you. You're supposed to be describing the next graph: the one that you, the author of this article, created from the results of Madeleine's survey. Or do you mean the graph that you, the audience, first saw when it flashed up on the screen at Helen Sword's ISSOTL keynote? Or the graph that you, the reader of this paragraph, are about to encounter for the first time? This is one of the 
problems with writing in the second person: the pronoun you could refer either to an othered author or, alternatively, to that author's imagined interlocutor or audience, which can vary according to context and purpose. Confused? You too.

But you soldier on in the second person mode you've chosen for this section of your article, as you must. Figure 2, which depicts relative pronoun usage and co-authorship patterns in all 70 articles published in TLI between 2013 and mid-2017, shows two striking shifts away from the patterns you observed in the 50 higher education journals in 2007: first, the percentage of co-authored articles has increased from 46 percent to 61 percent; and second, personal pronoun usage has soared from 50 percent to 88 percent. Madeleine pointed out to you another significant difference between the two data samples: whereas the co-authored higher education articles all have two to five authors, a significant proportion of the TLI articles (27 percent) have six to eight authors each, resulting in a much higher average number of authors overall (from 1.8 for the higher education articles to 3.2 for the TLI articles). While this bulge in authorship numbers can largely be explained by the fact that two special issues of TLI (in 2013 and 2017) were devoted to articles produced by teams of up to eight people working together as part of an experimental International Collaborative Writing Group process, you suspect that it also reflects the more collaborative ethos of SoTL researchers in general.

\section{Figure 2: Relative pronoun usage (first person or third person) and authorship patterns (single or multiple) in 70 articles from Teaching \& Learning Inquiry (2013-2017). Average number of authors per article: 3.2.}

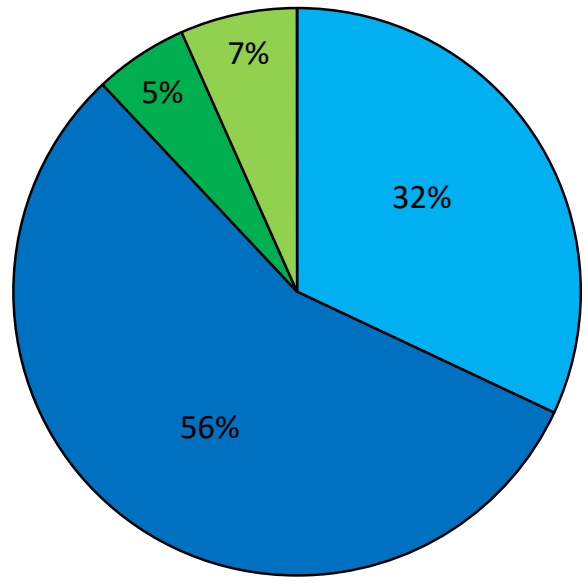

$\square$ single author (I)

$\square$ multiple authors (we)

$\square$ multiple authors (no we)

$\square$ single author (no I)

Discussing these results with Nancy and Gary after your keynote address_-sorry, reader, if you didn't actually deliver a keynote at ISSOTL 2017, you're probably not finding this sentence very relevant to you-you became curious as to whether the contrast between the two data sets has more to do with differences in genre (higher education research versus SoTL research) or with the historical moment that each graph represents (2007 versus 2017). In other words, do the two graphs reflect two distinctively different patterns of authorship, or has the entire discipline of higher education research (of 
which SoTL is a specialized subdiscipline) shifted towards increased first person pronoun usage over the past 10 years? You decided to find out.

\section{THE THIRD PERSON}

The author of this paper, Helen Sword, asked her research assistant, Madeleine Ballard, to replicate the 2007 survey of first person pronoun usage in 50 higher education journal articles, this time examining the 10 most recent articles from the same five higher education journals surveyed a decade earlier. The results were fascinating; Madeleine discovered a massive upsurge both in first person pronoun usage, from 54 percent to 94 percent, and in co-authorship numbers, from 46 percent to 88 percent (see Figure 3). Moreover, the average number of authors had increased from 1.8 to 3.2, with one article boasting no fewer than 11 named authors.

Figure 3: Relative pronoun usage (first person or third person) and authorship patterns (single or multiple) in $\mathbf{5 0}$ articles from five leading Higher Education research journals in 2016-2017 (10 articles per journal). Average number of authors per article: 3.2 .

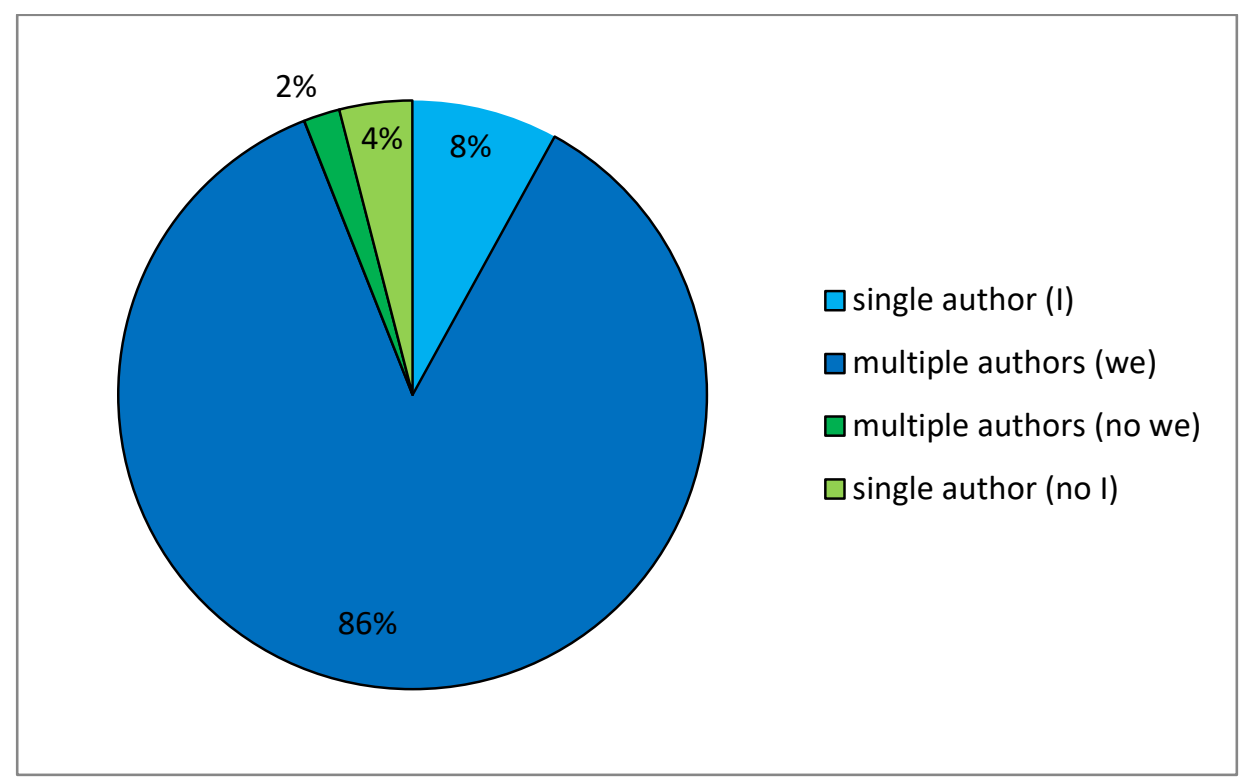

When Helen tried to write about this discovery in third person prose, using the pronoun she rather than $I$, we, or you, two strange things happened. First, she noticed herself inserting weighted adjectives such as fascinating, massive, and strange as a covert means of injecting her own voice and opinions into the writing. Second, she realized that she should not be employing the pronoun she or even referring to herself or Madeleine by name; that's not how third person academic prose generally works. Even when Helen syntactically merged herself with Madeleine to create a composite third person plural they, she still felt uncomfortably present in the article.

In fact, when academic authors talk about writing "in the third person," what they really mean most of the time is that no person is grammatically present. Sometimes, as in the first two paragraphs of this section, third person authors may allow opinion and emotion to colour their language (a mode 
frequently used, for example, by historians). More often, however, their aim is to distance themselves from human subjectivity altogether. Interestingly (whoops, there's authorial subjectivity rearing its pesky head again!), the increased proportion of co-authored articles in the two higher education samples closely parallels the increased proportion of first person pronoun usage in that same data set (see figure 4), a statistic that suggests an even stronger relationship between authorship numbers and pronoun usage than was evident in figure 1. Perhaps maintaining a rigidly third person stance becomes harder and harder to do as the number of authors increases? Or perhaps there is safety in numbers? For many academic authors, it appears, we feels less exposed than $I$, a step closer to the comforting anonymity of purely impersonal prose.

Figure 4: Relative authorship and pronoun usage patterns compared by journals and time period. (See figures 1-3 for details about the data samples).

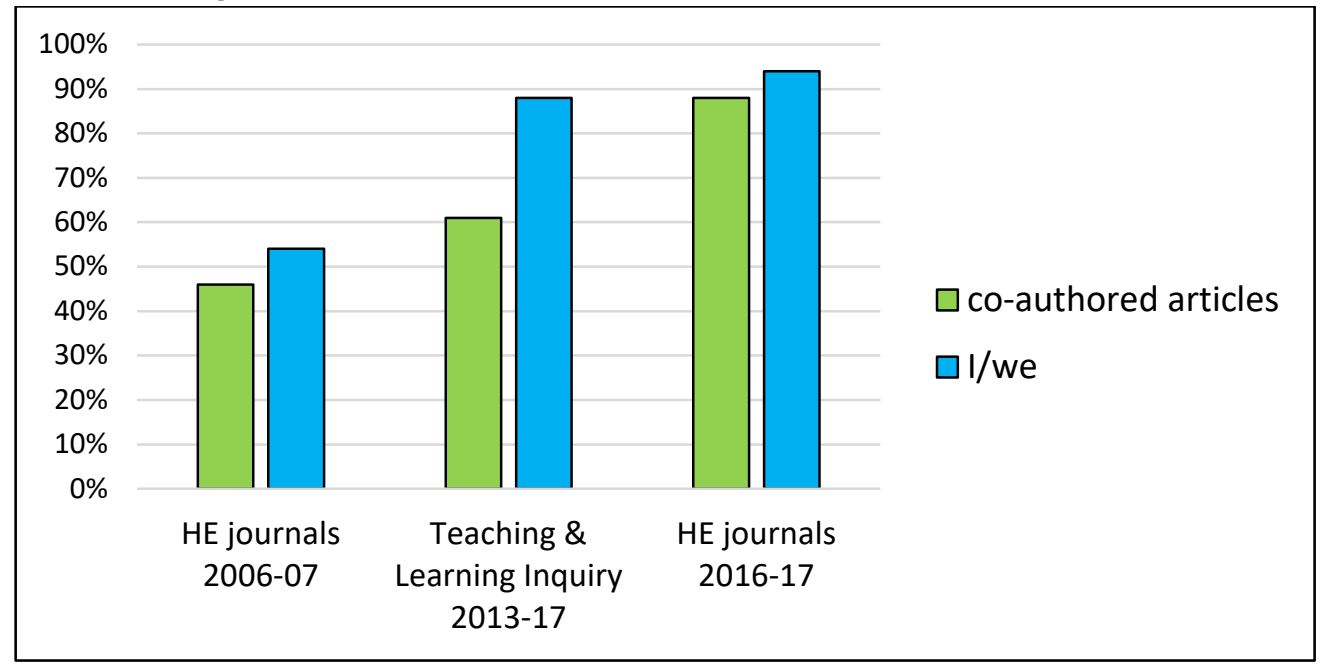

\section{THE MISSING PERSON}

The present study reports on the comparative frequency of first person pronoun usage in higher education and SoTL journals across a 10-year period (figures 1,2, and 3). Initially, it was hypothesized that the varying degree of first person pronoun usage between the 2006-2007 higher education articles (figure 1) and the 2013-2017 TLI articles (figure 2) could be explained by the more personal, introspective subject matter evident in SoTL scholarship, with its emphasis on the lived experience of the tertiary classroom. To test this hypothesis, an analysis of 50 recent higher education articles was undertaken, drawn from the same five top-ranked journals that had been examined in 2007. (The relative rankings of these journals had shifted in the interim; as of 2017, however, they were still the five most frequently cited higher education publications, according to journal-ranking authority SClmago.) A comparison of the 2006-2007 and 2016-2017 data (figures 1 and 3) shows a notable increase in personal pronoun usage over that 10 -year period, indicating that the differences initially observed between the higher education and SoTL articles (figures 1 and 2) are not in fact due to fundamental differences in subject matter or authorial orientation; instead, they more likely reflect an overall 
historical shift toward first person pronoun usage in both higher education and SoTL research.

The parallel increase in the average number of authors suggests, moreover, that personal pronoun usage and higher authorship numbers may be correlated (see figure 4). The causality behind this apparent correlation remains a matter of speculation. One explanation could be that the ever-increasing "publish-orperish" pressures imposed on academics by institutional audit mechanisms have led higher education scholars to seek out more frequent co-authoring opportunities as a means of boosting their publication metrics; this increase in co-authorship, in turn, has led to a proportionate rise in first person pronoun usage, in accordance with the "safety in numbers" principle. However, it is equally possible that there has been a historical shift toward increased first person pronoun usage in academic articles more generally, which in turn has enabled or accelerated a more collaborative higher education research culture. Further investigation of these matters would be a welcome contribution to the literature but is beyond the scope of this study.

\section{THE INCLUSIVE WE}

If the findings presented in this article are anything to go by, the first person has firmly established itself (herself, himself, themselves?) as the dominant pronoun convention both in SoTL scholarship and in higher education research more generally. Those of us who prefer the lively voices of real human beings to the dull dronings of agentless academic prose are sure to welcome this trend. However, let us pause for a moment before we politely escort the missing person out the door.

Aside from a handful of discipline-based studies - for example, by applied linguists and language teachers exploring issues of identity and authority (e.g. Chang \& Swales, 1999; Harwood, 2005a, 2005b, 2006; Hyland, 2002a, 2002b; Ivanic, 1998; Lorés-Sanz, 2011; Starfield, 2015; Tang \& Sugathi, 1999) and by gender and sexuality scholars highlighting the pronoun dilemmas faced by nonbinary students and scholars (e.g. McGlashan \& Fitzpatrick, 2018; Thieme \& Saunders, 2018)—there has been little published research on academic pronoun usage and even less consideration of how shifting pronoun conventions affect us in our day-to-day lives. As academics, we confront subtle decisions about pronoun usage every time we write. How much of a personal voice should we allow into our scholarship? (In SoTL publications, acceptable options range from "none" to "a lot.") What are the ethical implications of using the identity-flattening pronoun $w e$ in situations where there is clearly a power imbalance between coauthors? What rhetorical battering rams can we deploy, what subtle shibboleths can we whisper, when gate-keeping editors and reviewers righteously inform us that we're "not allowed" to refer to ourselves in our own writing? We-not just SoTL scholars, but academics across the disciplines-would benefit from a more robust discussion of such practical and philosophical conundrums.

The missing person still casts a long shadow, after all. Official style manuals including the APA Publication Manual, the ACS Style Guide, the AMA Manual, the CSE Manual, the Chicago Manual of Style, and the MLA Style Manual have long since endorsed first person pronoun usage; yet academic writing guides in virtually every discipline continue to caution against $I$ and we (Sword 2012). Well-meaning teachers and graduate advisors still instruct their students to de-personalize their prose; conservative copyeditors still utter knee-jerk interdictions. The first person stands tall in published SoTL scholarship but does not yet feel entirely at home in our wider academic environment. 
So what are we going to do about it?

\section{ACKNOWLEDGMENTS}

Although she did not in fact co-author this article, Madeleine Ballard provided crucial research assistance both in the preliminary data-gathering stage and at the later fact-checking and formatting stages. Thank you, Madeleine! I also acknowledge my stellar former research assistants Hannah Field and Louisa Shen, who contributed to the original 2007 study, and the three anonymous TLI reviewers whose thoughtful critiques helped me shape and strengthen this paper for publication.

Helen Sword is Professor and Director of the Centre for Learning and Research in Higher Education at the University of Auckland (NZ). Her recent books include Stylish Academic Writing (2012), The Writer's Diet (2016), and Air \& Light \& Time \& Space: How Successful Academics Write (2017).

\section{REFERENCES}

Chang, Y., \& Swales, J. (1999). Informal elements in English academic writing. In C. Candlin \& K. Hyland (Eds.), Texts, processes and practices (pp. 145-167). London, UK: Longman.

Harwood, N. (2005a). "Nowhere has anyone attempted ... In this article I aim to do just that": A corpus-based study of self-promotional / and we in academic writing across four disciplines. Journal of Pragmatics, 37(8), 1207-1231. https://doi.org/10.1016/j.pragma.2005.01.012

Harwood, N. (2005b). "We do not seem to have a theory ... the theory I present here attempts to fill this gap": Inclusive and exclusive pronouns in academic writing. Applied Linguistics, 26(3), 343-375. https://doi.org/10.1093/applin/ami012

Harwood, N. (2006). (In)appropriate personal pronoun use in political science: A qualitative study and a proposed heuristic for future research. Written Communication, 23(4), 424-450. https://doi.org/10.1177/0741088306293921

Hyland, K. (2002a). Authority and invisibility: Authorial identity in academic writing. Journal of Pragmatics, 34(8), 1091-1112. https://doi.org/10.1016/S0378-2166(02)00035-8

Hyland, K. (2002b). Options of identity in academic writing. ELT Journal, 56(4), 351-358. https://doi.org/10.1093/elt/56.4.351

Ivanic, R. (1998). Writing and identity: The discoursal construction of identity in academic writing. Amsterdam, NL: John Benjamins.

McGlashan, H., \& Fitzpatrick, K. (2018). "I use any pronouns, and I'm questioning everything else": Transgender youth and the issue of gender pronouns. Sex Education, 18(3), 239-252. https://doi.org/10.1080/14681811.2017.1419949

McInerney, J. (1984). Bright lights, big city. New York, NY: Vintage.

Lorés-Sanz, R. (2011). The construction of the author's voice in academic writing: The interplay of cultural and disciplinary factors. Text \& Talk: An Interdisciplinary Journal of Language, Discourse \& Communication Studies, 31(2), 173-193. https://doi.org/10.1515/text.2011.008

Rilke, R. M. (1995). Ahead of all parting: The selected poetry and prose of Rainer Maria Rilke (S. Mitchell, Trans.). New York, NY: Modern Library.

Stall, S. (2007). 100 cats who changed civilization: History's most influential felines. Philadelphia, PA: Quirk Books. Starfield, S. (2015). First person singular: Negotiating identity in academic writing in English. In D. N. Djenar, A. Mahboob, \& K. Cruickshank (Eds.), Language and identity across modes of communication (pp. 249-262). Boston, MA: De Gruyter Mouton.

Sword, H. (2009). Writing higher education differently: A manifesto on style. Studies in Higher Education, 34(3), 319-336. https://doi.org/10.1080/03075070802597101

Sword, H. (2012). Stylish academic writing. Cambridge, MA: Harvard University Press. 
Tang, R., \& Sugathi, J. (1999). The "I" in identity: Exploring writer identity in student academic writing through the first person pronoun. English for Specific Purposes, 18(51), S23-S39. https://doi.org/10.1016/S08894906(99)00009-5

Thieme, K., \& Saunders, M. (2018). How do you wish to be cited? Citation practices and a scholarly community of care in trans studies research articles. Journal of English for Academic Purposes, 32, 80-90. https://doi.org/10.1016/j.jeap.2018.03.010

(C) (i) Copyright for the content of articles published in Teaching \& Learning Inquiry resides with the authors, and copyright for the publication layout resides with the journal. These copyright holders have agreed that this article should be available on open access under a Creative Commons Attribution License 4.0 International (https://creativecommons.org/licenses/by/4.0). The only constraint on reproduction and distribution, and the only role for copyright in this domain, should be to give authors control over the integrity of their work and the right to be properly acknowledged and cited, and to cite Teaching \& Learning Inquiry as the original place of publication. Readers are free to share these materials - as long as appropriate credit is given, a link to the license is provided, and any changes are indicated. 